\title{
Pitfalls and clinical recommendations for the primary lumbar hernia based on a systematic review of the literature
}

\author{
S. van Steensel $\mathrm{I}^{1,2}$ - A. Bloemen ${ }^{1,3} \cdot$ L. C. L. van den $\mathrm{Hil}^{1,2} \cdot$ J. van den Bos ${ }^{1,2} \cdot$ G. J. Kleinrensink ${ }^{4} \cdot$ N. D. Bouvy $y^{1,2}$
}

Received: 18 April 2018 / Accepted: 1 October 2018 / Published online: 12 October 2018

(c) The Author(s) 2018

\begin{abstract}
Purpose The lumbar abdominal wall hernia is a rare hernia in which abdominal contents protrude through a defect in the dorsal abdominal wall, which can be of iatrogenic, congenital, or traumatic origin. Two anatomical locations are known: the superior and the inferior lumbar triangle. The aim of this systematic review is to provide a clear overview of the existing literature and make practical clinical recommendations for proper diagnosis and treatment of the primary lumbar hernia.

Methods The systematic review was conducted according to the PRISMA guidelines. A systematic search in PubMed, MEDLINE, and EMBASE was performed, and all studies reporting on primary lumbar hernias were included. No exclusion based on study design was performed. Data regarding incarceration, recurrence, complications, and surgical management were extracted.

Results Out of 670 eligible articles, 14 were included and additional single case reports were analysed separately. The average quality of the included articles was 4.7 on the MINORS index (0-16). Risk factors are related to increased intra-abdominal pressure. CT scanning should be performed during pre-operative workup. Available evidence favours laparoscopic mesh reinforcement, saving open repair for larger defects. Incarceration was observed in $30.8 \%$ of the cases and $2.0 \%$ had a recurrence after surgical repair. Hematomas and seromas are common complications, but surgical site infections are relatively rare. Conclusion The high risks of incarceration in lumbar hernias demand a relatively fast elective repair. The use of a mesh is recommended, but the surgical approach should be tailored to individual patient characteristics and risk factors.
\end{abstract}

Keywords Hernia $\cdot$ Abdominal wall hernia $\cdot$ Lumbar hernia $\cdot$ Laparoscopy $\cdot$ Prosthetic mesh

\section{Introduction}

Even in times of advanced medicine, it is possible that the rarity of a condition complicates diagnoses and treatment; such a challenge is found in the lumbar hernia. The lumbar hernia was first suggested by Barbette in the late seventeenth

N. D. Bouvy

n.bouvy@mumc.nl

1 Department of General Surgery, Maastricht University Medical Centre, PO Box 5800, 6202 AZ Maastricht, The Netherlands

2 NUTRIM School of Nutrition and Translational Research in Metabolism, Maastricht University, Maastricht, The Netherlands

3 Department of Surgery, VieCuri Medical Centre, Venlo, The Netherlands

4 Department of Neuroscience, Erasmus University Medical Center, Rotterdam, The Netherlands century and Garangeot published the first case in 1731. A lumbar hernia is a protrusion of intra-peritoneal or extraperitoneal contents through a defect of the posterolateral abdominal wall [1].

Anatomically, three types of lumbar hernia are identified; the superior lumbar hernia, the inferior lumbar hernia, and the diffuse lumbar hernia. The superior lumbar triangle, also known as the Grynfeltt-Lesshaft triangle, is bordered by the 12 th rib and posterior inferior serratus muscle superiorly, laterally by the posterior border of the internal oblique muscle, and medially by the anterior border of the erector spinae muscle [2]. The anatomic boundaries of the inferior lumbar triangle, generally known as Petit's triangle, are the iliac crest inferiorly, the medial border of the external oblique muscle on the lateral side, and medially the lateral border of the latissimus dorsi muscle [3] (see Fig. 1). The third anatomical type of lumbar hernia is not limited by the previously discussed anatomical structures, is of considerable size, and, therefore, designated as a diffuse lumbar hernia. 
Fig. 1 Anatomy of the dorsal abdominal wall, and boundaries of the inferior and superior lumbar space

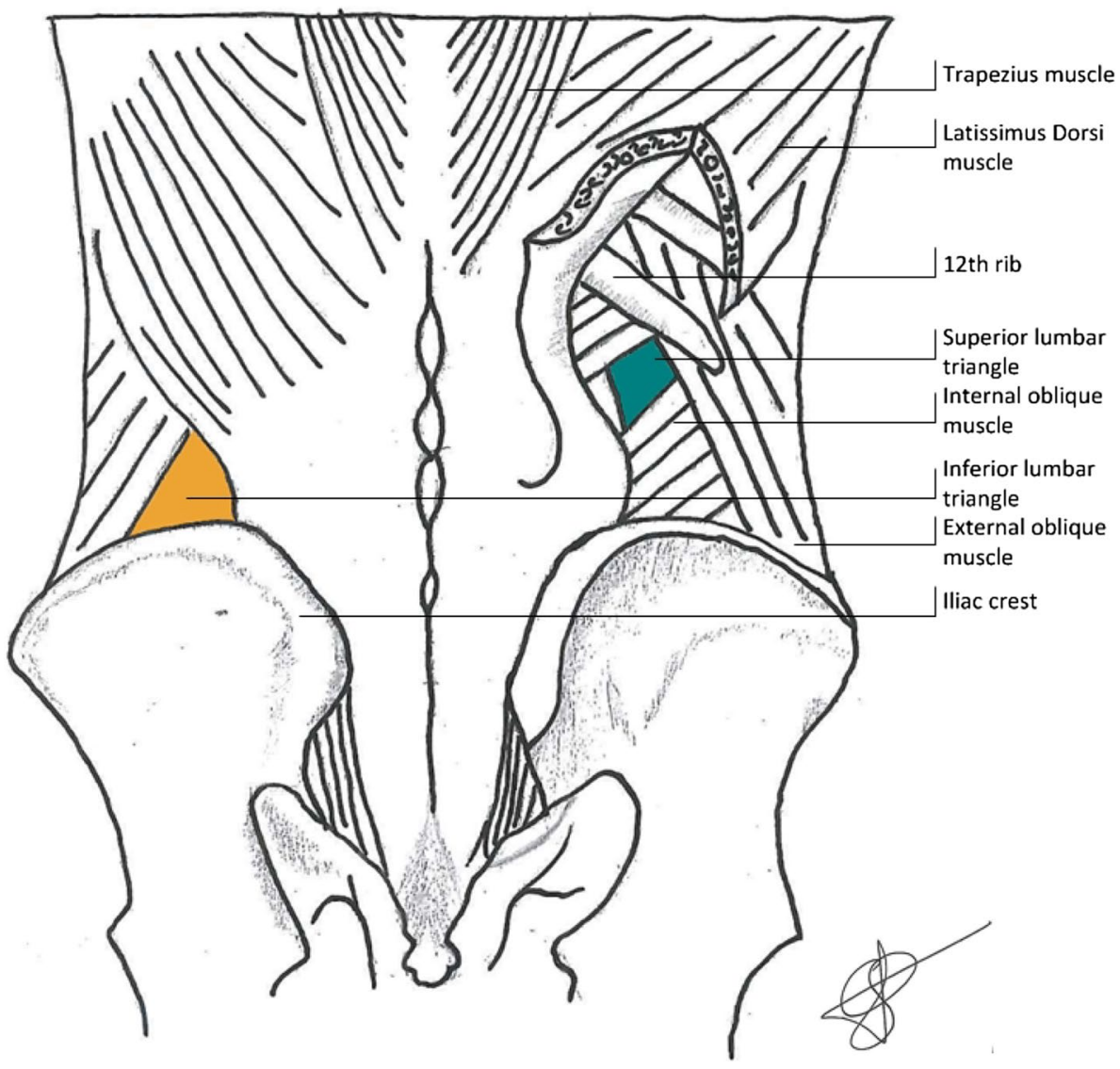

This is usually seen following a traumatic event or secondary to surgery. These secondary hernias are aetiologically distinguished from primary or spontaneous lumbar hernias and, therefore, fall outside the scope of this systematic review, which will only focus on primary lumbar hernias [4].

Predisposing factors for primary acquired hernias are similar to those of other hernias and related to an elevated intra-abdominal pressure such as pregnancy, obesity, ascites, or chronic bronchitis [4, 5], and weakness of the posterior abdominal wall caused by aging, muscle atrophy, and chronic debilitating disease. Extreme thinness and intense slimming may also predispose for the development of hernias $[4,5]$. Another major determinant for hernia formation is the size of the area at risk, which is determined by the size and form of the triangle, the length and angulation of the 12th rib, the size of the musculus quadratus lumborum, and the musculus serratus posterior. All these factors combined result in a higher prevalence in short, obese people with wide hips and more horizontal ribs resulting in larger triangles $[4,5]$.

Just like other abdominal wall hernias, the most common clinical presentation is a palpable, usually reducible mass, which increases in size when abdominal pressure rises. The mass may disappear when the patient assumes a supine position. Symptoms may be back pain or lumbago along the area of the distribution of the sciatic nerve, possibly accompanied by unspecific abdominal discomfort and fatigue. One in ten patients with lumbar hernia present with acute complications, such as bowel obstruction or urinary obstruction, requiring emergency intervention [4]. It is important to consider a broad differential diagnosis including tumours, such as lipomas, sarcomas or kidney mass, and infectious disorders, like abscesses and panniculitis. Furthermore, a pannicular lumbosacroiliac hernia or a hematoma should be kept in mind.

The rarity of primary lumbar hernia and the high risk of acute presentation prompted us to perform a systematic review of the literature on treatment options and management. Due to the differences in aetiology of the lumbar hernia, this systematic review focuses on the primary lumbar hernia. The aim is to provide a clear overview of the existing literature and make practical clinical recommendations for the proper diagnosis and treatment.

\section{Methods}

\section{Systematic search and study selection}

This systematic review was performed according to the PRISMA guidelines [6] and its protocol was registered 
online on Prospero [CRD42018085537]. PubMed, MEDLINE, and EMBASE were searched on the 8th of august 2017 using all search terms and synonyms for lumbar hernia, which are presented in Table 1 and all references were checked for possible eligible articles. All articles were screened based on title and abstract by two independent reviewers ( $\mathrm{SvS}$ and $\mathrm{JvdB}$ ). If eligible, the full text was screened by the same independent reviewers. Disagreement was settled by discussion between the reviewers and arbitrated by a third independent reviewer (AB) if necessary. All articles of added value reporting on primary or spontaneous lumbar hernia written in English, Dutch, or German were included and articles reporting on incisional, congenital, or traumatic lumbar hernias were excluded. Articles reporting on a single case were analysed separately. If, after rigorous search, no abstract or full text was retrievable, the article was ruled out. Because of the low number of publications expected to be found, a broad search was performed and restrictions were limited to a minimum to review all the available literature and provide the most extensive foundation for clinical recommendations as possible.

\section{Quality assessment}

In case of a case series reporting on lumbar hernias, the quality assessment was done using the methodological index for non-randomised studies (MINORS), which consist of eight criteria and four additional criteria in case of a comparative study. The items are scored 0 for not reported, 1 for reported but inadequate, and 2 for reported and adequate with a maximum score of 16 for non-comparative and 24 for comparative studies [7]. The quality assessment was performed by two independent reviewers ( $\mathrm{SvS}$ and $\mathrm{JvdB}$ ). Disagreement was settled by discussion and, if necessary, a third reviewer $(\mathrm{AB})$ was contacted for arbitration.

Table 1 Search terms used in the literature search

\begin{tabular}{ll}
\hline Search terms & \\
\hline Abdominal hernia (MesH) & Lumbar hernia \\
Abdominal hernia & Lumbar triangle \\
& Inferior lumbar triangle \\
& Superior lumbar triangle \\
& Dorsal hernia \\
& Petit \\
& Petit triangle \\
& Petit's triangle \\
& Petit hernia \\
& Grynfeltt-Lesshaft \\
& Grynfeltt-Lesshaft triangle \\
& Grynfeltt-Lesshaft hernia \\
\hline
\end{tabular}

\section{Data extraction}

In case of diversity in study design, outcomes, and reporting, the high heterogeneity would impair useful conclusions from a meta-analysis, and thus, a structured narrative synthesis of the extracted data will be performed. Data on diagnosis and treatment of primary lumbar hernia were extracted. If available, recurrence rates, patient characteristics, and complication rates were extracted from the articles using a standardised form. Case reports were analysed separately, because of unavoidable differences in design, manner of reporting results, and potential risk of bias.

\section{Results}

\section{Systematic search}

After the removal of duplicates, a total of 670 articles were identified for title and abstract screening (see Fig. 2). 547 articles were excluded leaving 28 articles for full-text screening, resulting in the inclusion of 14 [4, 8-20] articles in this systematic review, of which 5 had a prospective design [9, $10,12,13,17], 3$ a retrospective design $[8,18,19]$ and in 5 articles, the design was unclear $[4,11,14-16]$. In most cases, multiple types of lumbar hernia were included in the study, and in four studies, the aetiology of the lumbar hernia was not specified beyond lumbar or acquired $[8,9,11,16]$. Five studies $[9,10,13,16,19]$ used the open approach for the repair of the lumbar hernia, one study [8] only included patients with a laparoscopic repair, and three studies $[4,12$, 17] included both. Of the total population of 420 patients described, 85 patients were diagnosed with a spontaneous or primary lumbar hernia and 33 patients with a primary or acquired lumbar hernia not specified, leaving 118 patients in total. The follow-up ranged from 1 month to 170 months (see Table 2 for the patient and study characteristics).

\section{Quality assessment}

One comparative study scored 19 out of a possible 24 points on the MINOR index [17]. Regarding the non-comparative studies, the median MINOR score was 4 ranging from 1 to 9. All studies scored poorly on reporting loss to follow-up and unbiased endpoints. The duration of follow-up and the relevant endpoints were described adequately in most included studies (See Table 3).

\section{Diagnosis}

The gold standard for the diagnosis of a lumbar hernia is performing a CT scan, with a sensitivity of $98 \%$ based on its 


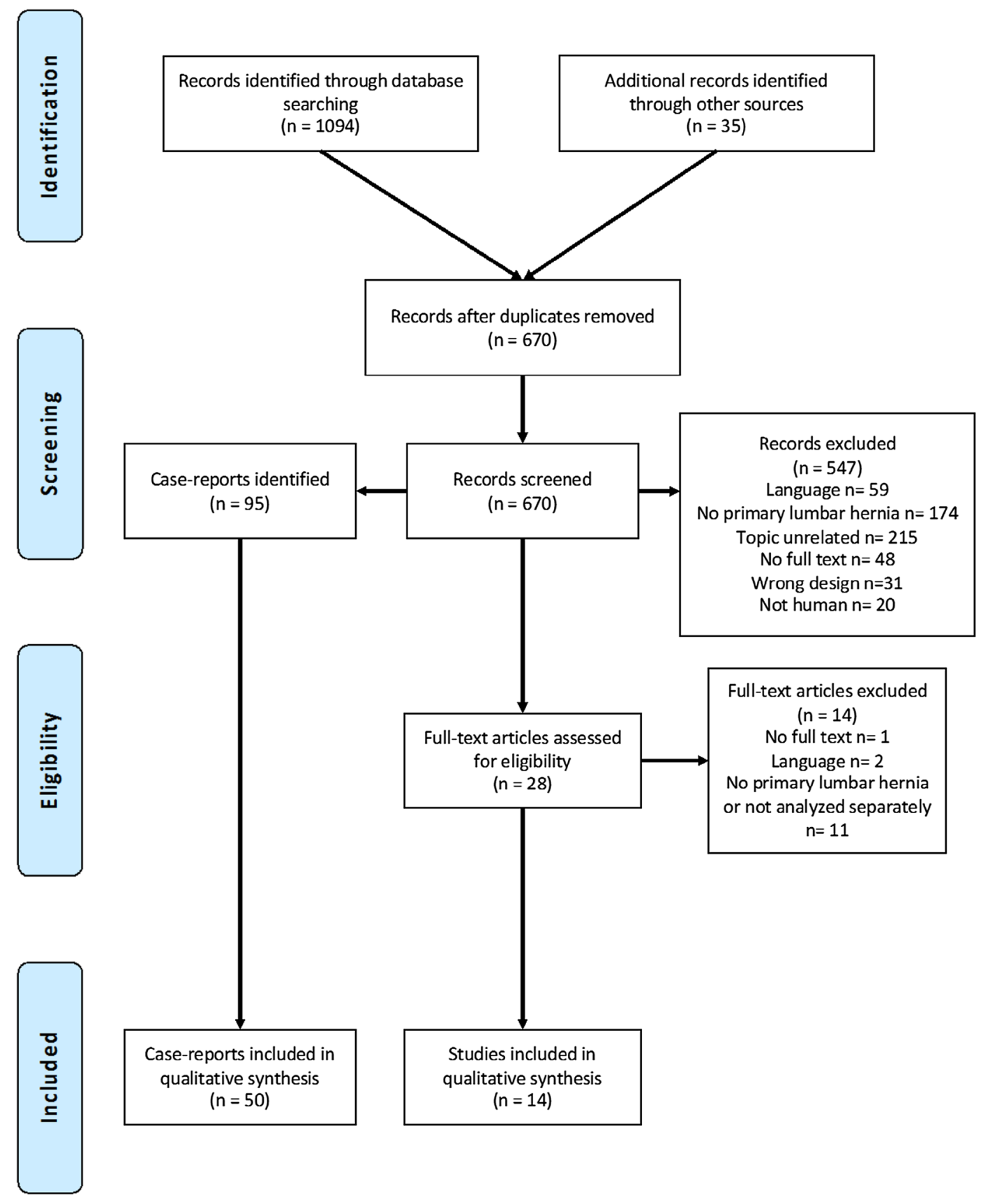

Fig. 2 PRISMA 2009 flow diagram

possibility (1) to distinguish between fascial and muscular layers, (2) to detect a defect in one of these layers, and (3) to assess the nature of the potential herniated content [5, 21-25]. Furthermore, CT scans are useful for diagnosing the asymptomatic non-palpable lumbar hernia [22]. This can influence the operative approach, because primary repair of lumbar hernias can be performed via the retroperitoneum [23]. The differentiation between a lumbar hernia and muscle atrophy should be made using CT scans. It is advisable to evaluate the patient with a lumbar hernia routinely and plan the surgery proper using CT imaging [5]. Studies that focus on the use of MRI specifically in the case of lumbar hernias have not been carried out [15]. Ultrasonography does not seem useful when a direct clinical suspicion is absent or in obese patients [5].

\section{Treatment}

Similar to all abdominal wall hernias, the lumbar hernia has a progressive character with an increase in size, back pain 


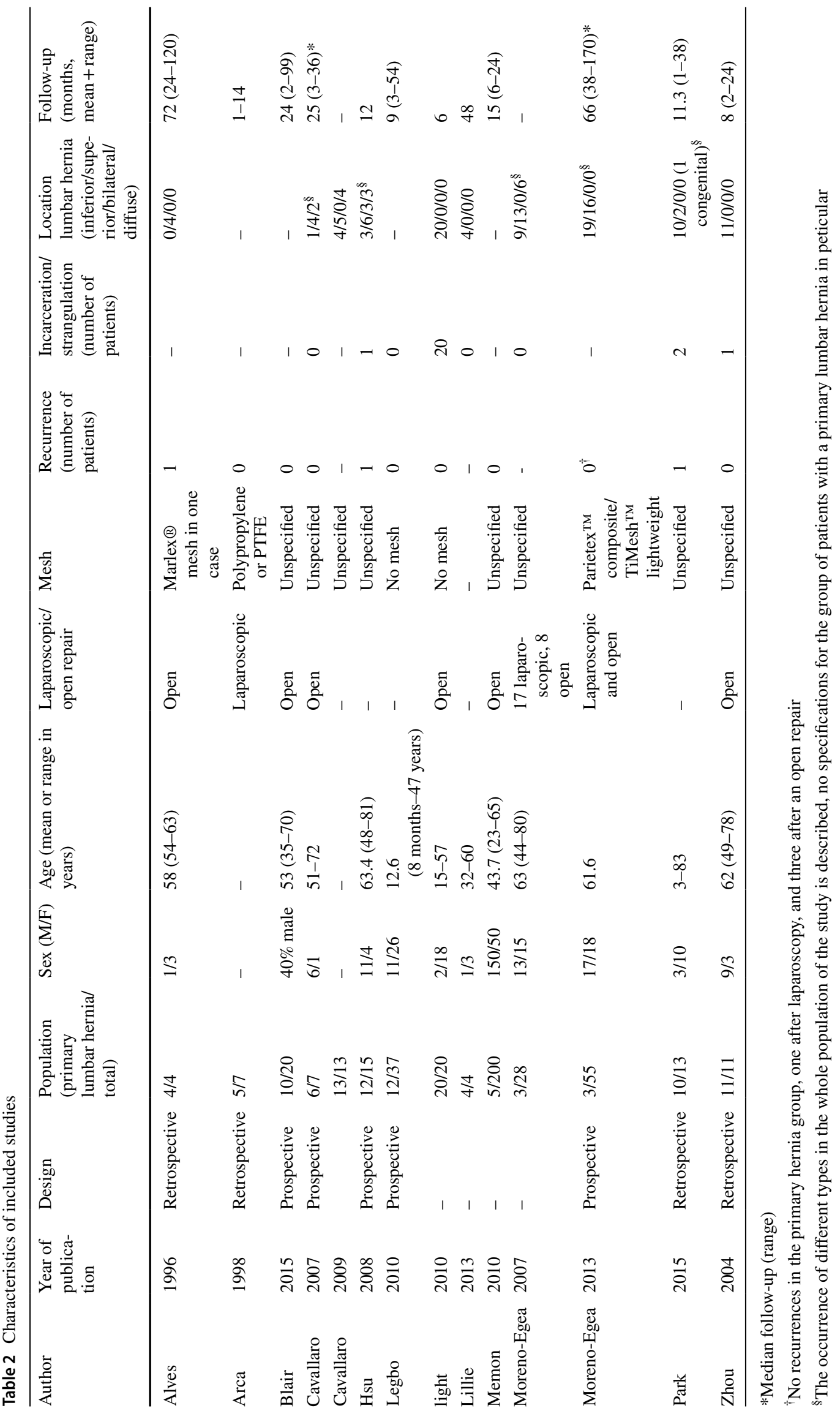




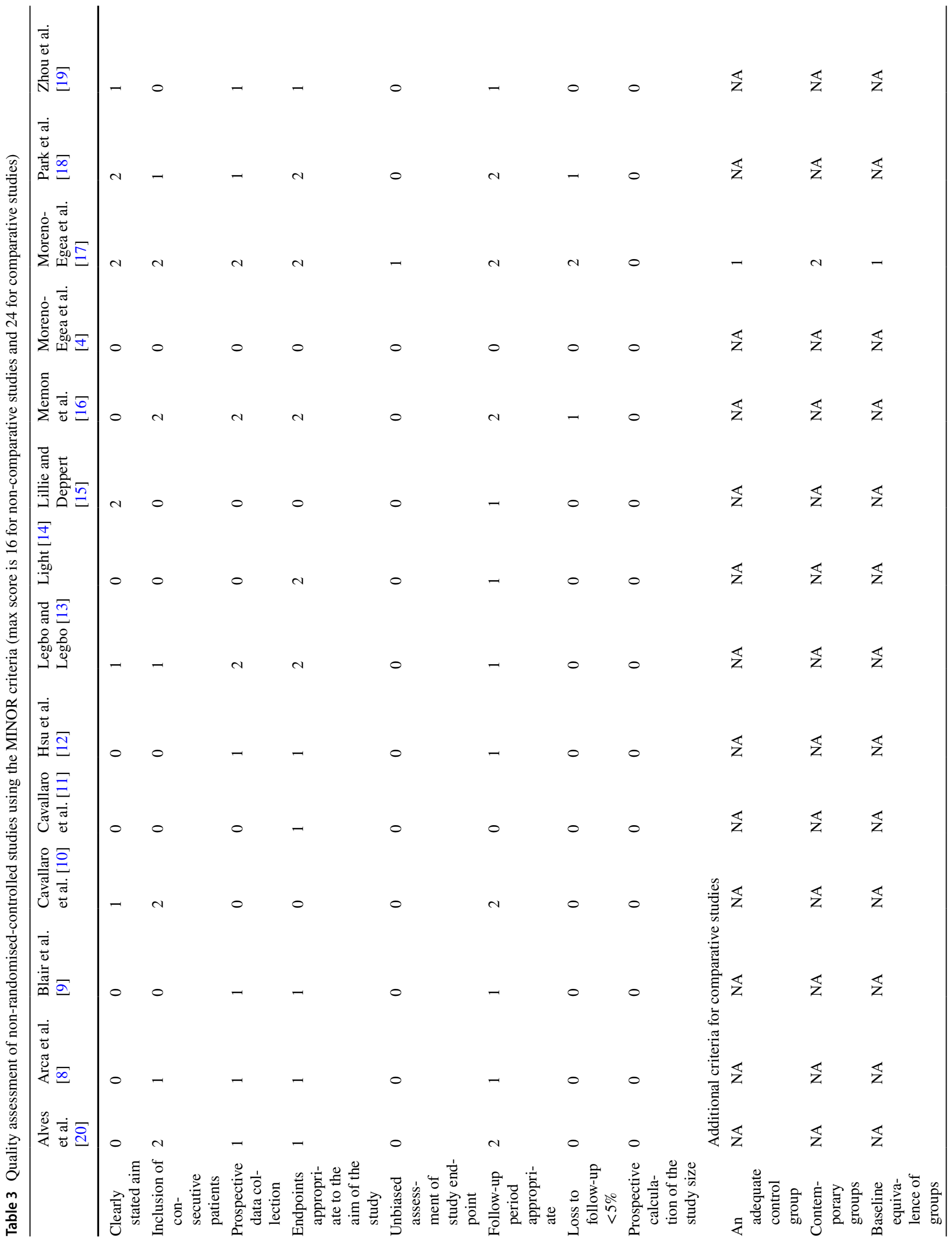




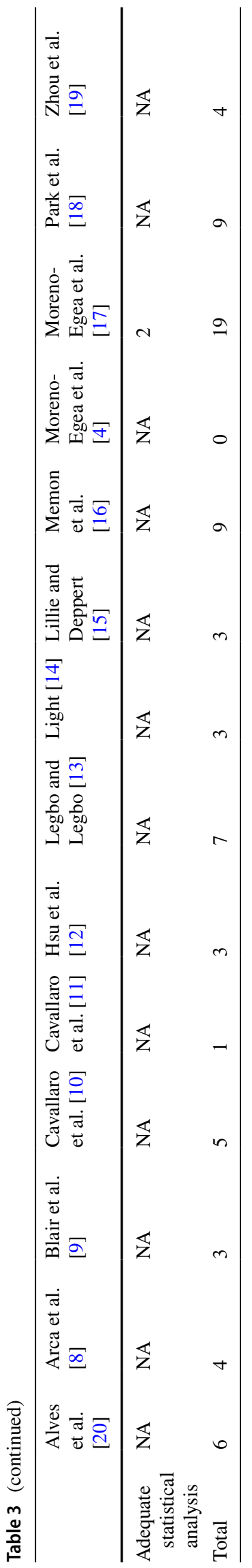

[17] and, sometimes, bowel obstruction [26, 27]. Predictors associated with an increased likelihood for recurrence are obesity and a defect size larger than $15 \mathrm{~cm}$ [28].

Operative repair with the elimination of the defect and reconstruction and reinforcement of the resilient abdominal wall, capable of resisting stress in the future, is probably the most effective treatment [5]. Surgical approach is presented with technical difficulties in defining the external edges of the fascial defect. The location, the lack of adequate fascia, and the weakness of the surrounding tissue result in problematic visualisation of the defect. Furthermore, the bony boundaries, in close proximity of the defect, are a limiting factor in repair [1, 8, 17].

Primary closure and mesh augmentation of the defect are the most important techniques. Primary closure of the defect has the potential to be effective in small hernias, but not in large lumbar hernias because of the high tension created over the defect in combination with the limited strength of the tissues surrounding the defect $[8,10,29]$. The literature does not elaborate much regarding the choice of mesh for lumbar hernia repair. Like the repair of other types of hernias, a coated mesh for intra-abdominal use or, otherwise, a lightweight mesh is recommended [17]. It was once suggested to use two meshes, one placed in a sublay and the other in an onlay technique, in a tension-free repair of the lumbar hernia [30]. Garg et al. investigated the use of a tension-free sutureless repair for lumbar hernias in a dorsal approach in three infants and one adult, and concluded that this method was easy, safe, and effective [31]. A trans-abdominal partial extra-peritoneal technique (TAPE) for repairing lumbar hernias has been reported. It is concluded that this technique was feasible and might be preferable to the open technique in complicated cases $[32,33]$. Other surgical techniques for lumbar hernia repair are use of a rotational flap or onlay flap. These techniques require extensive dissection and are accompanied by the risk of ischemia and muscle atrophy due to compromised vascularisation of the flap, which can result in a failed repair and a potentially larger defect than the original $[8,10,29]$.

Similar to other abdominal hernias, the use of synthetic meshes in a tension-free repair is widely accepted because of the experience in the other fields of abdominal wall surgery. Other advantages are its effectiveness and inexpensiveness $[8,10]$. The decision regarding the location of the mesh placement and the approach depends on the aetiology of the lumbar hernia, divided in acquired and primary lumbar hernias [10, 17]. Small primary lumbar hernias $(<5 \mathrm{~cm})$ [4] with well-defined borders, a normal lumbar anatomy, and without visceral content are good candidates for the pre-peritoneal approach. The pre-peritoneal laparoscopic approach seems feasible and safe, and, in contrast to the trans-abdominal retroperitoneal laparoscopy, does not require excessive mobilization of intra-abdominal structures, 
and avoids intra-peritoneal adhesions [34, 35]. MorenoEgea et al. confirmed in a prospective study that the general advantages of laparoscopic surgery apply to the repair of the lumbar hernia. The laparoscopic approach showed a significantly shorter hospital stay; earlier return to normal activity, less analgesic consumption and less pain both 1 and 6 months postoperatively [17]. In addition, Moreno-Egea et al. showed, in a series of 16 consecutive patients, that the mean final costs of a laparoscopic operation are significantly less when compared to the open approach [36]. The open approach can be reserved for large defects, in case of incarceration and when the laparoscopic approach has failed [4]. When placement of the mesh is difficult due to bordering bone structures and if the defect leaves no sufficient fascia for suture fixation, bone anchor fixation is a feasible and safe method [37].

\section{Obstruction/incarceration}

Eight studies reported on the incarceration or strangulation of a lumbar hernia, describing 78 patients in total $[4$, $10,12-15,18,19]$, of which 24 patients were classified as having an incarcerated hernia (30.8\%). One case of bowel incarceration and a case of a strangulated hernia with bowel obstruction were mentioned. Light et al. [38] reported on 20 cases of lumbar hernia in which incarcerated fat was observed.

\section{Recurrence}

In 11 studies [8-10, 12-14, 16-20] the recurrence rate was reported, of which seven studies [8-10, 13, 14, 16, 19] reported zero recurrences after surgery. Therefore, the mean recurrence rate was 2 out of 98 patients with a primary hernia (2.0\%). In the series of four patients of Alves et al. [20], one recurrence occurred after 10 days following a primary repair. Park et al. [18] reported one recurrence 6 months postoperatively, after repair with a mesh plug, but neglected to mention what type of lumbar hernia was repaired.

\section{Single case reports}

A total of 50 case reports $[5,26,27,34,38-85]$ regarding a primary lumbar hernia were included, describing 55 cases (see Table 4 for patient and study characteristics). In 49 patients, the location of the lumbar hernia was reported, and $34(69.4 \%)$ occurred in the superior lumbar triangle, $12(24.5 \%)$ in the inferior lumbar triangle, and $3(6.1 \%)$ in both locations. In 44 patients, the operation technique was described and 34 (77.3\%) were repaired using a mesh and $10(22.7 \%)$ lumbar defects were primary closed. In five case reports $[44,47,59,61,82]$, the patient was not operated for the lumbar hernia. 10 patients were operated
Table 4 Characteristics of the included case reports

\begin{tabular}{ll}
\hline Number of cases & 55 \\
Sex (M/F) & $23 / 28$ \\
Age (mean) & 63 \\
Location (superior/inferior/both) & $34 / 12 / 3$ \\
Location (left/right/bilateral) & $29 / 18 / 5$ \\
Mesh repair (occurrence/total reported) & $34 / 44$ \\
Operation (laparoscopic/open repair) & $10 / 22$ \\
Follow-up (range) & 7 days-24 months \\
Recurrence (occurrence /total reported) & $2 / 34$ \\
Incarceration and strangulation (occurrence/total & $12 / 40$ \\
reported) & \\
\hline
\end{tabular}

laparoscopically, and in 22 patients, an open repair was performed. The recurrence rate was $5.9 \%$. In one case [5], a recurrence occurred after 2 years following a primary open repair. The other case [60] describes a bilateral recurrence 1 month postoperatively, which occurred after an open repair with a polypropylene mesh. Two case reports [34, 73] described a seroma after mesh repair which was treated by needle aspiration. An incarceration occurred in 12 out of the 40 patients (29.3\%) of which occurrences of these symptoms were recorded.

\section{Discussion}

This is the first systematic review on primary lumbar hernias and offers the largest data set on this subject by including all studies concerning primary lumbar hernia regardless of design. The aim is to provide a clear overview of the available literature and make evidence based practical and clinical recommendations and to identify pitfalls regarding diagnosis and treatment.

Overall quality of the included studies assessed using the MINOR criteria was relatively low. This is a result of the design of the included studies, mostly case series, nonrandomised designs, or retrospective studies. A prospective calculation was lacking in all the included studies. Furthermore, was an unbiased evaluation of the endpoints using adequate blinding often not performed and was the loss to follow-up not mentioned in most studies.

The surgical approach should be tailored to the individual hernia characteristics. A laparoscopic pre-peritoneal approach is preferable in small, simple primary lumbar hernias leaving the open approach for the complex cases. In the repair of a lumbar hernia, the general advantages of a laparoscopic approach, regarding a faster postoperative recovery and pain reduction, apply. A possible alternative is suggested by Beffa et al. [86] the robotic trans-abdominal pre-peritoneal approach, which has potential advantages regarding lumbar hernia repair. 
Regarding mesh repair versus primary closure, no recommendations can be made based on the data presented in this review, but following the overwhelming evidence in hernia research, it seems clear that patients would benefit from a repair with a mesh. And above all should the choice of mesh be dictated by the surgical approach. For example, it is the extra-peritoneal repair of a lumbar hernia suitable for repair with a non-coated mesh, which is probably more cost-effective than coated meshes for intra-peritoneal placement. The recurrence rate is relatively high and with publication bias playing a major role that the true recurrence rate might even be higher. Most recurrences occurred after an open repair, but definitive conclusions cannot be drawn.

The percentage of incarceration in this type of hernia is considerably high. Although the design of the included studies increases the risk of publication bias, the incarceration rate found in the included studies and in the single case reports was similar. Macchi et al. found, in a recent anatomic-radiologic study, evidence for a "lumbar canal" after analysing a randomly selected series of CT scans of the abdomen. This lumbar canal is described as being a real musculoaponeurotic tunnel with a postero-anterior direction. It is suggested that the superior and inferior lumbar triangle are connected with the deep peritoneal opening or deep lumbar ring located at the superior lumbar triangle and the subcutaneous opening or superficial lumbar ring at the inferior lumbar triangle [87]. This "lumbar canal" and as well as a complex anatomic composition of multiple layers of the abdominal wall might increase the risk of incarceration. It is recommended that surgical correction is performed electively as early as possible and preferably by a surgeon with experience in the field of hernia surgery. This timeframe allows for adequate diagnostic imaging but minimizes the risk of incarceration. Although a clinical diagnosis suffices, a CT scan is regarded the gold standard to assess the extent of the lumbar hernia, the involved anatomical structures, the level of atrophy, and the possible content of the hernia.

The diagnosis and treatment of lumbar hernias are complicated by its low incidence, resulting in scarce experience and lack of consensus in the literature. Heterogeneity in the population, based on the subdivision in aetiology, increases this problem. Publication bias, due to the design of the included studies, might result in an overestimation of the complaints and complications of the patient at presentation, like incarceration. On the other hand, it can cause an underestimation of the recurrence rates. More high-quality research is needed, in which, unfortunately, is the incidence of a lumbar hernia a severely limiting factor. Centralising care for this rare entity would increase specialisation and produce the volumes needed for adequate research. Furthermore, cooperation between specialised abdominal wall centres would increase the awareness of this type of dorsal lumbar abdominal wall hernia.

\section{Conclusions}

The risks for incarceration in lumbar hernias are increased compared to the other hernias which requires relatively fast elective repair by a surgeon with experience in the field of hernia surgery. A laparoscopic pre-peritoneal repair with a mesh is recommended in lumbar hernia $<5 \mathrm{~cm}$, but the surgical approach in hernia $>5 \mathrm{~cm}$ should be tailored to individual patient characteristics and risk factors.

Funding None.

\section{Compliance with ethical standards}

Conflict of interest All authors declare that they have no conflict of interest.

Ethical approval For this study was approval from the institutional review board not required.

Statement of human rights Not applicable, since this is a literature study.

Informed consent Formal consent was not required for this study.

Open Access This article is distributed under the terms of the Creative Commons Attribution-NonCommercial 4.0 International License (http://creativecommons.org/licenses/by-nc/4.0/), which permits any noncommercial use, distribution, and reproduction in any medium, provided you give appropriate credit to the original author(s) and the source, provide a link to the Creative Commons license, and indicate if changes were made.

\section{References}

1. Burt BM, Afifi HY, Wantz GE, Barie PS (2004) Traumatic lumbar hernia: report of cases and comprehensive review of the literature. J Trauma Inj Infect Crit Care 57(6):1361-1370

2. Loukas M, El-Zammar D, Shoja MM, Tubbs RS, Zhan L, Protyniak B et al (2008) The clinical anatomy of the triangle of Grynfeltt. Hernia 12(3):227-231

3. Loukas M, Tubbs RS, El-Sedfy A, Jester A, Polepalli S, Kinsela $C$ et al (2007) The clinical anatomy of the triangle of Petit. Hernia 11(5):441-444

4. Moreno-Egea A, Baena EG, Calle MC, Martinez JA, Albasini JL (2007) Controversies in the current management of lumbar hernias. Arch Surgery 142(1):82-88

5. Suarez S, Hernandez JD (2013) Laparoscopic repair of a lumbar hernia: report of a case and extensive review of the literature. Surg Endosc 27(9):3421-3429

6. Moher D, Liberati A, Tetzlaff J, Altman DG, Group P (2009) Preferred reporting items for systematic reviews and meta-analyses: the PRISMA statement. BMJ 339:b2535

7. Slim K, Nini E, Forestier D, Kwiatkowski F, Panis Y, Chipponi J (2003) Methodological index for non-randomized studies (MINORS): development and validation of a new instrument. ANZ J Surg 73(9):712-716 
8. Arca MJ, Heniford BT, Pokorny R, Wilson MA, Mayes J, Gagner M (1998) Laparoscopic repair of lumbar hernias. J Am Coll Surg 187(2):147-152

9. Blair LJ, Cox TC, Huntington CR, Ross SW, Kneisl JS, Augenstein VA et al (2015) Bone anchor fixation in abdominal wall reconstruction: a useful adjunct in suprapubic and para-iliac Hernia repair. Am Surg 81(7):693-697

10. Cavallaro G, Sadighi A, Miceli M, Burza A, Carbone G, Cavallaro A (2007) Primary lumbar hernia repair: the open approach. Eur Surg Res 39(2):88-92

11. Cavallaro G, Sadighi A, Paparelli C, Miceli M, D’Ermo G, Polistena A et al (2009) Anatomical and surgical considerations on lumbar hernias. Am Surg 75(12):1238-1241

12. Hsu SD, Shen KL, Liu HD, Chen TW, Yu JC (2008) Lumbar hernia: clinical analysis of cases and review of the literature. Chir Gastroenterol 24(3):221-224

13. Legbo JN, Legbo JF (2010) Abdominal wall reconstruction using de-epithelialized dermal flap: a new technique. J Surg Techn Case Rep 2(1):3-7

14. Light HG (1983) Hernia of the inferior lumbar space. A cause of back pain. Arch Surg 118(9):1077-1080

15. Lillie GR, Deppert E (2010) Inferior lumbar triangle hernia as a rarely reported cause of low back pain: a report of 4 cases. $\mathbf{J}$ Chiropr Med 9(2):73-76

16. Memon MR, Shaikh AA, Memon SR, Jamro B (2010) Results of stoppa's sublay mesh repair in incisional and ventral hernias. JPMA J Pak Med Assoc 60(10):798-801

17. Moreno-Egea A, Alcaraz AC, Cuervo MC (2013) Surgical options in lumbar hernia: laparoscopic versus open repair. A long-term prospective study. Surg Innov 20(4):331-344

18. Park SH, Chung HS, Song SH (2015) Lumbar hernia in South Korea: different from that in foreign literature? Hernia 19(5):835-839

19. Zhou X, Nve JO, Chen G (2004) Lumbar hernia: clinical analysis of 11 cases. Hernia 8(3):260-263

20. Alves A Jr, Maximiano L, Fujimura I, Pires PW, Birolini D (1996) Grynfelt hernia. Arq Gastroenterol 33(1):32-35

21. Baker ME, Weinerth JL, Andriani RT, Cohan RH, Dunnick NR (1987) Lumbar hernia: diagnosis by CT. AJR Am J Roentgenol 148(3):565-567

22. Faro SH, Racette CD, Lally JF, Wills JS, Mansoory A (1990) Traumatic lumbar hernia: CT diagnosis. AJR Am J Roentgenol 154(4):757-759

23. Killeen KL, Girard S, DeMeo JH, Shanmuganathan K, Mirvis SE (2000) Using CT to diagnose traumatic lumbar hernia. AJR Am J Roentgenol 174(5):1413-1415

24. Salameh JR, Salloum EJ (2004) Lumbar incisional hernias: diagnostic and management dilemma. JSLS 8(4):391-394

25. Martin J, Mellado JM, Solanas S, Yanguas N, Salceda J, Cozcolluela MR (2012) MDCT of abdominal wall lumbar hernias: anatomical review, pathologic findings and differential diagnosis. Surg Radiol Anat SRA 34(5):455-463

26. Steerman SN, Steerman PH (2004) Scoliotic lumbar hernia as a cause of colonic obstruction. J Am Coll Surg 199(1):162

27. Teo KA, Burns E, Garcea G, Abela JE, McKay CJ (2010) Incarcerated small bowel within a spontaneous lumbar hernia. Hernia 14(5):539-541

28. Moreno-Egea A, Carrillo-Alcaraz A (2012) Management of non-midline incisional hernia by the laparoscopic approach: results of a long-term follow-up prospective study. Surg Endosc 26(4):1069-1078

29. Dowd CN (1907) Congenital Lumbar Hernia, at the triangle of Petit. Ann Surg 45(2):245-248
30. Bigolin AV, Rodrigues AP, Trevisan CG, Geist AB, Coral RV, Rinaldi N et al (2014) Petit Lumbar Hernia-a double-layer technique for tension-free repair. Int Surg 99(5):556-559

31. Garg CP, Sharma P, Patel G, Malik P (2011) Sutureless meshplasty in lumbar hernia. Surg Innov 18(3):285-288

32. Sun J, Chen X, Li J, Zhang Y, Dong F, Zheng M (2015) Implementation of the trans-abdominal partial extra-peritoneal (TAPE) technique in laparoscopic lumbar hernia repair. BMC Surg 15:118

33. Shekarriz B, Graziottin TM, Gholami S, Lu HF, Yamada H, Duh QY et al (2001) Transperitoneal preperitoneal laparoscopic lumbar incisional herniorrhaphy. J Urol 166(4):1267-1269

34. Habib E (2003) Retroperitoneoscopic tension-free repair of lumbar hernia. Hernia 7(3):150-152

35. Meinke AK (2003) Totally extraperitoneal laparoendoscopic repair of lumbar hernia. Surg Endosc 17(5):734-737

36. Moreno-Egea A, Torralba-Martinez JA, Morales G, Fernandez T, Girela E, Aguayo-Albasini JL (2005) Open vs laparoscopic repair of secondary lumbar hernias: a prospective nonrandomized study. Surg Endosc 19(2):184-187

37. Carbonell AM, Kercher KW, Sigmon L, Matthews BD, Sing RF, Kneisl JS et al (2005) A novel technique of lumbar hernia repair using bone anchor fixation. Hernia 9(1):22-25

38. Light D, Gopinath B, Banerjee A, Ratnasingham K (2010) Incarcerated lumbar hernia: a rare presentation. Ann R Coll Surg Engl 92(3):W13-W14

39. Ahmed ST, Ranjan R, Saha SB, Singh B (2014) Lumbar hernia: a diagnostic dilemma. BMJ Case reports 2014:15

40. Alcoforado C, Lira N, Kreimer F, Martins-Filho ED, Ferraz AA (2013) Grynfelt hernia. Arq Bras Cir Dig 26(3):241-3

41. Astarcioglu H, Sokmen S, Atila K, Karademir S (2003) Incarcerated inferior lumbar (Petit's) hernia. Hernia 7(3):158-160

42. Belekar DM, Dewoolkar VV, Desai AA, Butala UK (2014) Primary Grynfeltt's Hernia. Indian J Surg 76(2):145-147

43. Bickel A, Haj M, Eitan A (1997) Laparoscopic management of lumbar hernia. Surg Endosc 11(11):1129-1130

44. Cabello R, Cancho MJ, Monzo JI, Lopez I, Tabares J, Hernandez C (2008) Herniation of renal pelvis and ureteropelvic junction resulting from superior lumbar triangle hernia. Scand J Urol Nephrol 42(1):81-82

45. Cesar D, Valadao M, Murrahe RJ (2012) Grynfelt hernia: case report and literature review. Hernia 16(1):107-111

46. Chenoweth J, Vas W (1989) Computed tomography demonstration of inferior lumbar (Petit's) hernia. Clin Imaging 13(2):164-166

47. Coulier B (2011) Grynfelt hernia. JBR-BTR 94(2):99

48. Di Francesco F, Gourgiotis S, Solaini L (2010) A very simple technique to repair Grynfeltt-Lesshaft hernia. Hernia 14(4):439-441

49. Fogarty JD, Hafron JM, Melman A (2006) Renal obstruction caused by herniation of renal pelvis and ureteropelvic junction through superior lumbar triangle hernia (Grynfeltt hernia). Urology 67(3):620-621

50. Guillem P, Czarnecki E, Duval G, Bounoua F, Fontaine C (2002) Lumbar hernia: anatomical route assessed by computed tomography. Surg Radiol Anat SRA 24(1):53-56

51. Hafner CD, Wylie JH Jr, Brush BE (1963) Petit's lumbar hernia: repair with Marlex mesh. Arch Surg 86:180-186

52. Heniford BT, Iannitti DA, Gagner M (1997) Laparoscopic inferior and superior lumbar hernia repair. Arch Surg 132(10):1141-1144

53. Hide IG, Pike EE, Uberoi R (1999) Lumbar hernia: a rare cause of large bowel obstruction. Postgrad Med J 75(882):231-232

54. Horovitz IL, Schwarz HA, Dehan A (1986) A lumbar hernia presenting as an obstructing lesion of the colon. Dis Colon Rectum 29(11):742-744

55. Ipek T, Eyuboglu E, Aydingoz O (2005) Laparoscopic management of inferior lumbar hernia (Petit triangle hernia). Hernia 9(2):184-187 
56. Kim DJ, Park JW (2015) A rare nonincisional lateral abdominal wall hernia. Ann Surg Treat Res 88(2):111-113

57. Lai SW, Chen KY (2015) Lumbar hernia of Grynfeltt's triangle. Indian J Med Res 141(6):844

58. Lau H, Lee F (2002) Mesh plug hernioplasty of superior lumbar hernia. Ann Coll Surg Hong Kong 6(1):25-27

59. Lawdahl RB, Moss CN, Van Dyke JA (1986) Inferior lumbar (Petit's) hernia. AJR Am J Roentgenol 147(4):744-745

60. Lichtenstein IL (1986) Repair of large diffuse lumbar hernias by an extraperitoneal binder technique. Am J Surg 151(4):501-504

61. Luo P, He XW, Chen QY, Hong H, Yang L (2016) Femoral intertrochanteric fracture with spontaneous lumbar hernia: a case report. Trauma Mon 21(5):e25132

62. Mingolla GP, Amelio G (2009) Lumbar hernia misdiagnosed as a subcutaneous lipoma: a case report. J Med Case Rep 3:9322

63. Mismar A, Al-Ardah M, Albsoul N, Younes N (2013) Underlay mesh repair for spontaneous lumbar hernia. Int J Surg Case Rep 4(6):534-536

64. Naidoo M, Singh B, Ramsaroop L, Satyapal KS (2003) Inferior lumbar triangle hernia: case report. East Afr Med J 80(5):277-280

65. Nam SY, Kee SK, Kim JO (2011) Laparoscopic transabdominal extraperitoneal mesh repair of lumbar hernia. J Korean Surg Soc 81(Suppl 1):S74-S77

66. Ng SS, Ng NC, Liu SY, Lee JF (2006) Radiology for the surgeon. Soft-tissue case 58: incarcerated Grynfeltt hernia. Can J Surg 49(2):129-130

67. Pachani AB, Reza A, Jadhav RV, Mathews S (2011) A primary idiopathic superior lumbar triangle hernia with congenital right scoliosis: a rare clinical presentation and management. Int J Appl Basic Med Res 1(1):60-62

68. Pitale A, Laughlin V (2002) Superior lumbar hernia of Grynfellt. Postgrad Med J 78(922):472

69. Ploneda-Valencia CF, Cordero-Estrada E, Castaneda-Gonzalez LG, Sainz-Escarrega VH, Varela-Munoz O, De la Cerda-Trujillo LF et al (2016) Grynfelt-Lesshaft hernia a case report and review of the literature. Ann Med Surg (Lond) 7:104-106

70. Rehman S, Rooh-ul-Muqim RH, Hassan R, Zarin M, Wazir MA, Aurangzeb M (2009) Inferior lumbar hernia of Petit in a patient with neurofibromatosis type-1. Pak J Med Sci 25(6):1015-1017

71. Sharma P (2009) Lumbar hernia. Med J Armed Forces India 65(2):178-179

72. Shiiki S, Kuwata Y, Kashihara E, Ueda U, Fuchimoto S, Orita K (1991) A case of superior lumbar hernia. Jpn J Surg 21(6):696-699
73. Skrekas G, Stafyla VK, Papalois VE (2005) A Grynfeltt hernia: report of a case. Hernia 9(2):188-191

74. Sofiene A, Amin M, Baraket O, Houcine M, Daghfous A, Rebai W et al (2013) Computed tomography demonstration of an incarcerated lumbur hernia. La Tunisie Med 91(10):614

75. Solaini L, di Francesco F, Gourgiotis S, Solaini L (2010) A very simple technique to repair Grynfeltt-Lesshaft hernia. Hernia 14(4):439-441

76. Sundaramurthy S, Suresh HB, Anirudh AV, Rozario AP (2016) Primary lumbar hernia: a rarely encountered hernia. Int J Surg Case Rep 20:53-56

77. Tsujino $T$, Inamoto $T$, Matsunaga $T$, Uchimoto $T$, Saito K, Takai $\mathrm{T}$ et al (2015) Idiopathic lumbar hernia: a case report. [Japanese]. Hinyokika kiyo. Acta Urol Jpn 61(11):449-453

78. Uei T, Suzuki K, Nakano K, Kurokawa K, Fukabori Y, Yamanaka $H$ (1999) Usefulness of magnetic resonance imaging for the diagnosis of superior lumbar hernia: a case report. [Japanese]. Hinyokika kiyo. Acta Urol Jpn 45(12):839-842

79. Walgamage TB, Ramesh BS, Alsawafi Y (2015) Case report and review of lumbar hernia. Int J Surg Case Rep 6C(1):230-232

80. Wei CT, Chen YS, Sun CK, Hsieh KC (2014) Single-incision laparoscopic total extraperitoneal repair for a Grynfeltt hernia: a case report. J Med Case Rep 8(16):16

81. Witherspoon J, Chakravartty S, Parry CR, Williams GL, Stephenson BM (2012) Open sutureless lumbar hernia repair using a 'memory ring' patch. Hernia 16(2):227-228

82. Xu T, Zhang S, Wang H, Yu W (2013) Lumbar hernia associated with chronic obstructive pulmonary disease (COPD). Pak J Med Sci 29(3):874-876

83. Yamaguchi S, Tsutsumi N, Kusumoto E, Endo K, Ikejiri K, Yamashita Y et al (2013) Lumbar hernia treated with lightweight partially absorbable mesh: report of a case. Fukuoka Igaku Zasshi 104(12):575-579

84. Zadeh JR, Buicko JL, Patel C, Kozol R, Lopez-Viego MA (2015) Grynfeltt Hernia: a deceptive lumbar mass with a lipoma-like presentation. Case Rep Surg 2015:954804

85. Claus CMP, Nassif LT, Aguilera YS, Ramos EB, Coelho JCU (2017) Laparoscopic repair of lumbar hernia (Grynfelt): technical description. Arq Bras Cir Dig 30(1):56-9

86. Beffa LR, Margiotta AL, Carbonell AM (2018) Flank and Lumbar hernia repair. Surg Clin N Am 98(3):593-605

87. Macchi V, Porzionato A, Morra A, Picardi EE, Stecco C, Loukas $M$ et al (2016) The triangles of Grynfeltt and Petit and the Lumbar tunnel: an anatomo-radiologic study. Hernia 21:369-376 